\title{
A randomised controlled comparison of early post-pyloric versus early gastric feeding to meet nutritional targets in ventilated intensive care patients
}

\author{
Hayden White ${ }^{1}$, Kellie Sosnowski ${ }^{1}$, Khoa Tran ${ }^{1}$, Annelli Reeves ${ }^{2}$ and Mark Jones ${ }^{3}$
}

\author{
1Department of Critical Care, Logan Hospital, University of Queensland, Armstrong Road, Meadowbrook, Brisbane, 4131, Australia \\ 2Department of Nutrition Services, Logan Hospital, Armstrong Road, Meadowbrook, Brisbane, 4131, Australia \\ ${ }^{3}$ School of Population Health, University of Queensland, 15 Butterfield Street, Herston, 4006, Australia \\ Corresponding author: Hayden White, hayden_white@health.qld.gov.au
}

Received: 3 Aug 2009 Revisions requested: 1 Oct 2009 Revisions received: 10 Oct 2009 Accepted: 25 Nov 2009 Published: 25 Nov 2009

Critical Care 2009, 13:R187 (doi:10.1186/cc8181)

This article is online at: http://ccforum.com/content/13/6/R187

(c) 2009 White et al.; licensee BioMed Central Ltd.

This is an open access article distributed under the terms of the Creative Commons Attribution License (http://creativecommons.org/licenses/by/2.0), which permits unrestricted use, distribution, and reproduction in any medium, provided the original work is properly cited.

\section{Abstract}

Introduction To compare outcomes from early post-pyloric to gastric feeding in ventilated, critically ill patients in a medical intensive care unit (ICU).

Methods Prospective randomized study. Ventilated patients were randomly assigned to receive enteral feed via a nasogastric or a post-pyloric tube. Post-pyloric tubes were inserted by the bedside nurse and placement was confirmed radiographically.

Results A total of 104 patients were enrolled, 54 in the gastric group and 50 in the post-pyloric group. Bedside post-pyloric tube insertion was successful in $80 \%$ of patients. Patients who failed post-pyloric insertion were fed via the nasogastric route, but were analysed on an intent-to treat basis. A per protocol analysis was also performed. Baseline characteristics were similar for all except Acute Physiology and Chronic Health Evaluation II (APACHE II) score, which was higher in the postpyloric group. There was no difference in length of stay or ventilator days. The gastric group was quicker to initiate feed 4.3 hours (2.9 - 6.5 hours) as compared to post-pyloric group 6.6 hours (4.5 - 13.0 hours) $(P=0.0002)$. The time to reach target feeds from admission was also faster in gastric group: 8.7 hours (7.6 - 13.0 hours) compared to 12.3 hours (8.9 - 17.5 hours). The average daily energy and protein deficit were lower in gastric group $73 \mathrm{Kcal}(2-288 \mathrm{Kcal})$ and $3.5 \mathrm{~g}(0-15 \mathrm{~g})$ compared to $167 \mathrm{Kcal}(70-411 \mathrm{Kcal})$ and $6.5 \mathrm{~g}(2.8-17.3 \mathrm{~g})$ respectively but was only statistically significant for the average energy deficit $(P=0.035)$. This difference disappeared in the per protocol analysis. Complication rates were similar.

Conclusions Early post-pyloric feeding offers no advantage over early gastric feeding in terms of overall nutrition received and complications

Trial Registration Clinical Trial: anzctr.org.au:ACTRN12606000367549

\section{Introduction}

Adequate nutritional support plays a significant role in the outcome of critically ill patients [1]. Furthermore, it is generally accepted that enteral feeding is preferable to parenteral feeding [2-4]. Benefits of enteral feeding may include improvements in intestinal structure and function, prevention of bacterial translocation and infective complications with lower morbidity and cost [5-7]. There is also evidence that early enteral feeding is beneficial and is recommended in a number of guidelines $[1,3,8]$.
Delivery of nutrition via the nasogastric route may be problematic because a significant percentage of intensive care unit (ICU) patients suffer from bowel motility disorders leading to high gastric residual volumes (GRV) and under nutrition [9]. Furthermore, there is a concern that gastric feeding may lead to pulmonary aspiration $[10,11]$. One potential solution to this problem is the insertion of transpyloric feeding tubes. Small bowel (SB) feeding has the theoretical benefit of improved nutrition and lower aspiration and pneumonia rates $[8,10]$. However, complications such as misplacement of the small 
bore feeding tube into the lung with resultant pneumothorax are not rare [12-14]. In addition, insertion of post-pyloric tubes can be time-consuming and costly leading to delays in the initiation of feeds.

A number of post-pyloric insertion techniques have been described. The use of endoscopy or fluoroscopy has a relatively high success rate but is limited by availability, cost and often the need to transfer patients out of the ICU [15-19]. Furthermore, regional ICUs may not have ready access to endoscopy. In fact, Heyland and colleagues recommended postpyloric feeding as a routine only in those institutions where it could be conveniently and hastily established [20]. Several bedside techniques have been trialled with varying success [21-23]. Some studies have used dedicated physicians or dieticians to place post-pyloric tubes; however, providing 24-hour service may be unachievable. Training ICU nurses to insert SB tubes can overcome delays in feeding and potentially improve overall patient nutrition.

The aim of our study was to compare early gastric with postpyloric feeding in ventilated, critically ill patients in a regional ICU. Our primary end-points included: the success rate of nurse initiated insertion of post-pyloric tubes, the time taken to insert the tube, time to reach goal feeds and total nutrition received over ICU stay as a proportion of the calculated ideal. As part of the secondary analysis, we compared complication rates between groups including incidence of ventilator associated pneumonia (VAP), GRV and mortality.

\section{Materials and methods}

A single-site, prospective, randomised, controlled trial was conducted over a period of 12 months to compare gastric with post-pyloric feeding in ventilated, critically ill patients. The study setting was an eight-bed regional ICU. The Princess Alexandra Hospital Human Research Ethics Committee gave approval to conduct the investigation. Each patient or their next of kin provided written informed consent to participate.

All patients over 18 years of age admitted to ICU and expected to require mechanical ventilation for more then 24 hours were considered for inclusion. Exclusion criteria included ischaemic bowel, bowel obstruction, exacerbation of inflammatory bowel disease, acute variceal bleeding and patients deemed to be at high risk for anastomotic leak. Patients remained in the study until enteral feeding was ceased or they were discharged from the ICU.

Ventilated patients were randomly assigned to receive enteral feed via a nasogastric or a post-pyloric tube. Randomisation was achieved using a computer-generated random number sequence and a sealed opaque envelope technique. Patients were managed by a number of physicians, most of who were not involved in the study.
All enteric feeding tubes were placed by the bedside nurse. All participants irrespective of allocated group received a nasogastric tube (size 12, 14 or 16) positioned into the stomach. The post-pyloric group received a Corflo ${ }^{\circledR}$-Ultra Lite unweighted feeding tube (VIASYS MedSystems, Wheeling, IL, USA) - 10 FR $109 \mathrm{~cm}$ for patients less than $80 \mathrm{~kg}$, or $10 \mathrm{FR}$ $140 \mathrm{~cm}$ for patients greater than $80 \mathrm{~kg}$ inserted into either the duodenum or jejunum.

All patients received their feeding tubes as soon as possible. ICU nursing staff were trained by the principle researchers or the ICU clinical facilitator to insert the post-pyloric tubes using a blind insertion technique and were required to pass a competency test [24].

\section{Insertion of post-pyloric tube}

In order to limit bias, all participants received 500 mg erythromycin intravenously prior to insertion of the enteric tubes. The insertion of the post-pyloric tube commenced after at least 30 minutes of drug administration. The patient was placed in a semi-supine position at $30^{\circ}$. The Corflo ${ }^{\circledR}$-Ultra Lite feeding tube was inserted into the stomach to a length of approximately $45 \mathrm{~cm}$. Placement was confirmed by auscultating the stomach while insufflating air. As per the manufacturer's instructions, the tube was flushed with $2 \mathrm{ml}$ water to lubricate the guide wire. The tube was advanced very slowly until a further $15 \mathrm{~cm}$ of tube had been inserted. The frequent insertion of 5 to $10 \mathrm{ml}$ air checked for kinking or misplacement. The tube continued to be advanced until it reached $90 \mathrm{~cm}$ at the nare for a patient under $80 \mathrm{~kg}$, or $110 \mathrm{~cm}$ for a patient weighing more than $80 \mathrm{~kg}$. Abdominal radiography confirmed correct positioning. If the tube was not successfully placed after three attempts, further attempts were abandoned, and the patient was fed via the nasogastric route.

An enteral feeding algorithm which prescribed the appropriate type of feed and target rate was developed by the dietetic department. Height was used to estimate the ideal body weight or adjusted body weight for obese patients. The algorithm prescribed $30 \mathrm{kcal} / \mathrm{kg}$ of ideal body weight as this was comparable with 1.3 times the resting energy expenditure as determined by indirect calorimetry [25]. The protein requirement selected for the algorithm was $1.5 \mathrm{~g} / \mathrm{kg}$ ideal body weight, except in the case of liver and renal failure where the requirement was provided at 1 to $1.2 \mathrm{~g} / \mathrm{kg}[26,27]$.

Enteral feeds were commenced at $40 \mathrm{ml} /$ hour. The nasogastric tube was aspirated every four hours. If the gastric residual was less than $200 \mathrm{ml}$ after four hours, the rate was increased to the recommended target rate. Nasogastric aspirates of greater than $200 \mathrm{ml}$ warranted the use of prokinetic agents. Initially, metoclopramide $10 \mathrm{mg}$ every six hour was prescribed. Erythromycin $250 \mathrm{mg}$ twice daily was added if large aspirates persisted. If GRV remained above $200 \mathrm{ml}$ in the gastric group, a post-pyloric feeding tube was inserted and the feeding 
regime recommenced. Despite these measures, some participants were unable to successfully absorb enteral feed. These patients progressed to parenteral nutrition.

Once enrolled in the study, demographic data was collected including age, sex and primary diagnosis. An Acute Physiologic and Chronic Health Evaluation (APACHE II) score was determined. Procedural detail included the total time taken to successfully place the post-pyloric tube and the number of attempts required. Times were documented at the commencement of enteral feed and the achievement of the target rate of feed. Other variables recorded included the amount of gastric residual at four-hourly intervals. All episodes of use of prokinetic medication (metoclopramide and erythromycin) were recorded.

Patient outcome data including length of ICU stay and the total number of ventilated and enteral feeding hours was documented. Diagnosis of VAP was based on: new onset (after 48 hours) of fever, leukocytosis, new pulmonary infiltrates on chest radiograph, increased pulmonary secretions and a clinical pulmonary infection score above six $[28,29]$.

Analysis was performed using Stata/IC, version 10 for Windows (StataCorp LP, College Station, TX, USA). Continuous variables are reported as medians and inter-quartile range and compared using a Wilcoxon rank-sum test. A multiple regression model was used to compare the continuous outcomes of the study with adjustment for differences in baseline variables. For positively skewed outcome data, a log transformation was used to remove skew prior to regression analysis. Nutritional outcomes collected on a daily basis were averaged over the follow-up period for individual patients prior to analysis. Fisher's exact test was used to compare binary variables and logistic regression was used to compare mortality rates in the two treatment groups. The primary analysis was by intentionto-treat, however, a secondary per-protocol analysis was also performed. A sample size of 50 patients in each treatment group was pre-specified to have $90 \%$ power to detect a halving of the time to reaching goal feeds. This calculation assumed a level of significance of $5 \%$ and a modest lost to follow up rate of $10 \%$. Patients were randomly assigned to the two treatment groups using a computer-generated random list.

\section{Results}

A total of 108 patients were randomised, 57 in the gastric group and 51 in the post-pyloric group (Table 1). Of the 108 participants randomised, four were randomised in error and were excluded and two required total parenteral nutrition (TPN) support. Data from 104 patients was analysed. There were 10 patients in the post-pyloric group who did not receive

Table 1

\begin{tabular}{|c|c|c|}
\hline Variable & Gastric group Median (IQR) & Post-pyloric group Median (IQR) \\
\hline Age & $54(40-63)$ & $50(45-70)$ \\
\hline $\operatorname{Sex}(M: F)$ & $28: 26$ & $24: 26$ \\
\hline APACHE II score & $24.5(20-28)$ & $30(25-35)^{a}$ \\
\hline Length of stay in days & $5.02(1.98-9.99)$ & $5.3(2.73-9.89)$ \\
\hline Ventilator days & $3.92(1.5-8.54)$ & $3.93(2.3-8.38)$ \\
\hline Number of interal feed days & $3.92(1.05-7.88)$ & $3.63(1.89-6.92)$ \\
\hline \multicolumn{3}{|l|}{ Diagnoses: $\mathrm{n}(\%)$} \\
\hline \multicolumn{3}{|l|}{ Medical } \\
\hline Sepsis & $7(13)$ & $9(18)$ \\
\hline Cardiac arrest & $9(17)$ & $5(10)$ \\
\hline Respiratory infection & $6(11)$ & $13(26)$ \\
\hline COAD & $4(7)$ & $4(8)$ \\
\hline Other & $21(39)$ & $16(32)$ \\
\hline \multicolumn{3}{|l|}{ Surgical } \\
\hline Trauma & $6(11)$ & $2(4)$ \\
\hline Other & $1(2)$ & $1(2)$ \\
\hline
\end{tabular}

$\mathrm{APACHE}=$ Acute Physiologic and Chronic Health Evaluation $\mathrm{COAD}=$ Chronic Obstructive Airways Disease; $\mathrm{F}=$ female; IQR $=$ interquartile range; $M=$ male.

a $P=0.005$. 
a post-pyloric tube and four patients in the gastric group that did receive a post-pyloric tube. Of the patients in the postpyloric group who did not receive a post-pyloric tube, 10 were attempted without success, giving an overall success rate of $80 \%$. APACHE II scores for the successful and unsuccessful groups were similar. However, there was a significant difference between the GRV of the group where a post-pyloric tube could not be passed, ie 297 (232 to 442) ml/day compared with 126 (42 to 284$) \mathrm{ml} /$ day in the successful group $(P=$ 0.027).

On intent-to-treat analysis, there was no difference in the length of stay or ventilator days between groups (Table 2). In terms of the primary outcomes the gastric group was quicker to initiate feed as compared with post-pyloric group. The time to reach target feeds from admission was also faster in the gastric group although time to goal from initiation of feeds was similar suggesting the difference is related to the procedure itself rather than feeding intolerance. The average daily energy deficit was lower in the gastric group. There was evidence that a delay in initiation of feeding contributed to this result because the deficits on day one were higher in the post-pyloric group but not significantly so.

Baseline characteristics demonstrated that the post-pyloric group were sicker compared with the gastric group (Table 1). The APACHE II scores were higher and there was an increased incidence of diabetes three (6\%) compared with six (12\%), acute renal failure nine (17\%) compared with 12 (24\%) and vasopressor use 20 (37\%) compared with 27 (54\%) in the post-pyloric group. Higher APACHE II scores were associated with higher energy and protein deficits.
Adjusting for these discrepancies led to a non-significant difference in energy deficit between the two groups (Table 3).

Complication rates were similar between groups. Average daily GRV were similar although there was a trend toward higher residuals in the post-pyloric group: 190 (55 to 301) $\mathrm{ml}$ compared with 111 (43 to 275) $\mathrm{ml}(P=0.3)$ in the gastric group. There was also evidence that higher APACHE II score was associated with increased daily average nasogastric aspirate (by $3 \%$ for each unit increase in APACHE II score). A comparison of average daily GRV by position of tube (duodenum versus jejunum) showed no difference $(P=0.96)$. In terms of VAP, there were 16 events in total, 5 in the postpyloric group and 11 in the gastric group $(P=0.18)$.

Drugs that affect gastric motility were recorded. Number of days on fentanyl, morphine, metaclopramide or erythromycin was similar in the two groups: 2 ( 0 to 5.5 ) days in the gastric group; 2 (0 to 4 ) days in post-pyloric group $(P=0.7)$. Number of days on either metaclopramide or erythromycin was similar in the two groups: 0 ( 0 to 4.5$)$ days in the gastric group; 0 ( 0 to 2$)$ days in the post-pyloric group $(P=0.6)$. The number of deaths were 5 in the gastric group versus 11 in the pyloric group giving an odds ratio of 2.86 (95\% confidence interval $(\mathrm{Cl})=0.92$ to $8.89, P=0.069)$. When adjusted for apache score the odds ratio is $2.15(95 \% \mathrm{Cl}=0.65$ to $7.07, P=$ 0.20).

A per-protocol analysis was performed in order to correct for failure of insertion of post-pyloric tube (Tables 4 and 5). Patients who actually received a post-pyloric tube $(n=44)$ were compared with patients who did not $(n=60)$. Nutritional differences demonstrated during the intent-to-treat analysis

Table 2

\begin{tabular}{|c|c|c|c|}
\hline Variable & $\begin{array}{l}\text { Gastric group Median (IOR) } \\
n=54\end{array}$ & $\begin{array}{l}\text { Post-pyloric group Median (IQR) } \\
\mathrm{n}=50\end{array}$ & $P$ value \\
\hline Goal feed rate (ml/hour) & $74(69-81)$ & $71.5(59-79)$ & 0.13 \\
\hline Time to initiate feed from admission or ventilation in hours & $4.3(2.9-6.5)$ & $6.6(4.5-13.0)$ & $0.0002^{\mathrm{a}}$ \\
\hline Time to reach goal from initiation of feeds in hours & $4.3(4.0-5.0)$ & $4.1(3.4-5.0)$ & 0.3 \\
\hline Time to reach goal from admission or ventilation in hours & $8.7(7.6-13.0)$ & $12.3(8.9-17.5)$ & $0.004^{b}$ \\
\hline Average daily energy required in Kcal & $1588(913-1892)$ & $1463(1232-1804)$ & 0.7 \\
\hline Average daily energy deficit in Kcal & $73(2-288)$ & $167(70-411)$ & 0.035 \\
\hline Day 1 energy deficit in Kcal & $8(0-178)$ & $48(0-361)$ & 0.5 \\
\hline Average daily protein required in grams & $69(45-87)$ & $63(50-78)$ & 0.5 \\
\hline Average daily protein deficit in grams & $3.5(0-15)$ & $6.5(2.8-17.3)$ & 0.11 \\
\hline Day 1 protein deficit in grams & $1(0-4)$ & $3(0-13)$ & 0.4 \\
\hline
\end{tabular}

aA comparison adjusting for age and Acute Physiologic and Chronic Health Evaluation (APACHE) II score was also significant $(P<0.001)$, bA comparison adjusting for age and APACHE II score was also significant $(P=0.011)$.

IQR $=$ interquartile range. 
Table 3

\begin{tabular}{llll}
\hline \multicolumn{2}{l}{ Multiple regression analysis of average daily energy deficit } & & \\
\hline Variable & Estimate $^{\mathrm{a}}$ & $\mathbf{9 5 \%}$ confidence interval & $\boldsymbol{P}$ value \\
\hline Post-pyloric group & & 0.094 \\
Age & 1.19 & $0.96-1.48$ & 0.9 \\
APACHE II score & 1.00 & $0.99-1.01$ & 0.003 \\
\hline
\end{tabular}

APACHE $=$ Acute Physiologic and Chronic Health Evaluation.

aEstimate based on a ratio where 1.0 indicates no difference, ${ }^{b}$ Compared with gastric group.

disappeared when examined on a per-protocol basis although gastric feeding still showed a trend toward higher average nutritional intake.

\section{Discussion}

The effectiveness of post-pyloric as compared with gastric feeding has been examined in a number of studies. In general, the results have largely been equivocal. Both $\mathrm{Ho}$ and colleagues and Marik and colleagues confirmed this in two metaanalyses [30,31]. Individual studies have produced varying results. Montejo and colleagues found calorie intake to be similar between the nasogastric and nasojejunal group [11]. On the other hand, Kearns and colleagues found the post-pyloric route supplied more calories while Neumann and colleagues found the opposite [32,33]. With the high incidence of gastroparesis present in ICU patients (up to 50\%) it seems counterintuitive that gastric feeding can be as successful if not more than post-pyloric feeding [34,35]. Several reasons have been proposed to explain this observation including the longer time taken to insertion of post-pyloric tubes and therefore, later onset of feeding, the potential for more frequent tube related complications in patients fed via the SB (occlusion, dislodgment, accidental withdrawal) and tube position (i.e. duodenal versus jejunal).

We found that patients fed via a nasogastric tube had a shorter time to initiation of feed and time to reach goal feed and lower average daily energy deficit as compared with the post-pyloric group. Although statistically significant, the difference in energy deficit in absolute terms was only 6\%, which may not be clinically significant. Our findings compared favourably to other studies where percentage of daily nutritional targets delivered varied from 56 to $80 \%$ and time to achieve full nutritional targets varied from 23 to 43 hours in the postpyloric group [11,32,33,36-38]. This was despite the fact that the APACHE II scores in our study were higher than in previous studies.

There are several possible explanations for the observed differences. Firstly, in $20 \%$ of cases, post-pyloric tube insertion was unsuccessful and these patients were fed via the nasogastric route (see below). As analysis was by intent to treat, they were analysed in the post-pyloric group. To adjust for these cases, we performed a protocol-based analysis, which found the groups to be equivalent (although the trend favoured the gastric fed patients). Secondly, there was a delay in reaching goal feeds in the post-pyloric compared with the gastric group, which although not statistically significant may have influenced total nutritional intake. Thirdly, previous studies have noted a greater incidence of tube displacement in post-pyloric fed patients leading to frequent interruption of feeding.

Lastly, the effect of severity of illness on the gastrointestinal system is variable [34,39]. Although we know of no prospective studies linking severity of illness to the ability to absorb feeds, Nguyen and colleagues found that APACHE II score

Table 4

Patient characteristics (per protocol analysis)

\begin{tabular}{lll}
\hline Variable & $\begin{array}{l}\text { No post-pyloric tube } \\
\text { Median (IOR) }\end{array}$ & $\begin{array}{l}\text { Post-pyloric tube } \\
\text { Median (IOR) }\end{array}$ \\
\hline Age & $53(42-64)$ & $56(40-67)$ \\
Sex (M:F) & $35: 29$ & $19: 25$ \\
APACHE II score & $26(21-31.5)$ & $28.5(22.5-33.5)$ \\
Length of stay in days & $4.97(2.0-10.0)$ & $5.57(2.8-9.8)$ \\
Ventilator days & $3.43(1.6-8.4)$ & $4.92(2.3-8.2)$ \\
Number of interal feed days & $3.1(1.3-6.6)$ & $4.02(1.9-7.5)$
\end{tabular}

$\mathrm{APACHE}=$ Acute Physiologic and Chronic Health Evaluation; $\mathrm{F}=$ female; $\mathrm{IQR}=$ inter-quartile range; $\mathrm{M}=$ male. 
Table 5

\begin{tabular}{|c|c|c|c|}
\hline Variable & $\begin{array}{l}\text { No post-pyloric tube } \\
\text { Median (IQR) } \\
\mathrm{n}=60\end{array}$ & $\begin{array}{l}\text { Post-pyloric tube } \\
\text { Median (IQR) } \\
n=44\end{array}$ & $P$ value \\
\hline Goal feed rate $(\mathrm{ml} / \mathrm{hour})$ & $74(66-79)$ & $71.5(62-81)$ & 0.6 \\
\hline Time to initiate feed from admission or ventilation in hours & $5.0(3.6-9.4)$ & $5.8(4.1-10.0)$ & $0.25^{a}$ \\
\hline Time to reach goal from initiation of feeds in hours & $4.1(3.8-5.4)$ & $4.1(3.6-5.3)$ & 0.9 \\
\hline Time to reach goal from admission or ventilation in hours & $9.5(7.6-16.3)$ & $10.5(8.4-16.1)$ & $0.21^{b}$ \\
\hline Average daily energy deficit in Kcal & $79(2-340)$ & $149(74-369)$ & $0.11^{\mathrm{c}}$ \\
\hline Average daily protein deficit in grams & $4.3(0-16.3)$ & $6.6(2.9-14.8)$ & $0.23^{d}$ \\
\hline
\end{tabular}

$\mathrm{APACHE}=$ Acute Physiologic and Chronic Health Evaluation; IQR = inter-quartile range. $\mathrm{a} P=0.19 ; \mathrm{b} 0.57 ;{ }^{\mathrm{c}} 0.10 ; \mathrm{d} 0.15$ (after adjustment for age and APACHE II score).

was associated with delayed gastric emptying [39]. The APACHE II scores of our patients were higher then most prior studies suggesting that they were sicker. We also found a significant difference in APACHE II scores between the groups (Table 1). Once results were adjusted for APACHE II score, the difference in nutritional outcomes was not apparent.

A principle motivation for the use of SB feeding is the high incidence of gastroparesis in ICU populations (50\% ventilated and $80 \%$ head injured) $[35,40]$. There are numerous potential reasons for this including abdominal surgery, haemodynamic instability, burns, electrolyte abnormalities, fluid overload and the use of vasoactive drugs or analgo-sedation and it is thought that by bypassing the stomach, feeding tolerance can be improved $[41,42]$. Most ICU feeding studies use GRV as a surrogate for gastric emptying and motility. The utility and significance of this measurement is controversial and depends on a number of factors. Indeed, the relation between GRV and gastric emptying is weak $[43,44]$. The level of aspirate considered excessive is largely arbitrary and can vary between 150 and $400 \mathrm{ml}$ [45]. Furthermore, up to $25 \%$ of patients with GRV more than $150 \mathrm{ml}$ have a normal gastric emptying and can continue on prokinetics.

Neither Ho and colleagues nor Marik and colleagues reported on GRV in their analyses [30,31]. Many individual studies report the number of episodes of high GRV rather than the absolute amount. Montejo and colleagues found that up to $50 \%$ of patients had high GRV in the gastric group compared with $2 \%$ in the post-pyloric group [11]. Neumann and colleagues, however, found similar results between groups [33]. Differences in definitions of high GRV limit comparison between studies. Montejo and colleagues considered a GRV of $300 \mathrm{ml}$ significant whereas, Neumann and colleagues used $200 \mathrm{ml}$ as a cut off. A high incidence of GRV is considered important because it may increase the risk of aspiration and VAP. In our study we reported on average GRV and found no significant difference, although the GRV in the post-pyloric group was higher. This may partially be explained by the higher APACHE II score and therefore, increased likelihood of gastroparesis in that group. Furthermore, some tubes in the postpyloric group were in the duodenum rather then jejunum. However, when stratified by tube position, there was no difference in GRV. These findings were in keeping with Heyland and colleagues who similarly failed to find a relation between SB tube position and amount of reflux [10]. Dysmotility in critically ill patients is known to affect the small bowel, and may lead to significant reflux.

Although not statistically significant the mortality rate was higher in the post-pyloric group. The reasons for this are not obvious. As noted, the APACHE II scores were higher in postpyloric group but even correcting for this, the odds ratio for death was 2.15. All deaths were reviewed and reported to the ethics review committee. No evidence could be found to link the insertion of post-pyloric tubes to the deaths. Furthermore, the mortality rate of $20 \%$ in the post-pyloric group was not unexpected given their high APACHE II scores. We therefore do not believe there is any evidence that the insertion of postpyloric tubes contributed to the deaths of any patient.

Other major complications from post-pyloric tube insertion were rare and we had no significant episodes. We examined the incidence of VAP because there is some evidence that SB feeding may be beneficial. Although this seems a reasonable assumption, there is little strong evidence from the literature to support it $[10,30,32,46]$. We found a similar incidence of VAP between the groups although there was a trend toward a lower incidence in the post-pyloric group. Our numbers were insufficient to reach statistical significance. The diagnosis of VAP is controversial and diagnostic criteria vary between studies. We did not examine the incidence of aspiration.

Endoscopic guided post-pyloric tube insertion is costly, is not universally available and can lead to significant delays in initiation of feeds. In fact, delays of more then 24 hours are the rule 
$[11,33,47]$. The mean time to reach goal feed in the studies reviewed by $\mathrm{Ho}$ and colleagues ranged between 23 and 43 hours [30]. We demonstrated that by employing a nurse-initiated bedside insertion method and an aggressive approach to enteral feeding, the time to reach goal feeds can be reduced, as compared with other studies. Our success rate of $80 \%$ compares well with other techniques although some have reported higher insertion rates $[24,48,49]$. Other non-invasive methods have similar outcomes [50-53]. In most instances, the post-pyloric tube was inserted on the first attempt. Despite reports of a high incidence of malposition, there were no episodes of lung insertion.

This study has several limitations. Firstly, doctors were not blinded to treatment group. Secondly, nurses with varying experience were responsible for insertion of post-pyloric tubes. This was intentionally done to reflect the day to day practice of the ICU. Thirdly, there was a $20 \%$ failure for insertion of post-pyloric tubes. The blind insertion technique was chosen because access to endoscopic insertion is limited and would have significantly delayed initiation of feeds. This reflects our current practice in the ICU. Fourthly, difference in APACHE II scores suggest the post-pyloric group contained sicker patients, which may have influenced feeding and outcome. And finally, our patient population is largely medical and therefore, may not represent findings in a surgical group of patients.

\section{Conclusions}

Our data largely support the findings of previous meta-analyses, that early post-pyloric feeding is not superior to gastric feeding in the medical ICU population. Whether post-pyloric feeding can be effective in selected patients such as those unable to tolerate gastric feeding is unclear. We also demonstrated that bedside nursing staff can successfully and safely place post-pyloric tubes in the majority of patients, potentially reducing delays in the initiation of feeds.

\section{Key messages}

- Early post-pyloric feeding is no more effective than early gastric feeding.

- Blind insertion of naso-jejunal feeding tubes by bedside nursing staff is highly effective.

\section{Competing interests}

The authors declare that they have no competing interests.

\section{Authors' contributions}

HW and KS conceived, managed study and drafted manuscript. AR supplied nutritional data and contributed to manuscript. KT participated in its design and coordination and helped to draft the manuscript. MJ participated in the design of the study and performed the statistical analysis. All authors read and approved the final manuscript.

\section{Acknowledgements}

The authors would like to thank the nursing staff of the Logan Intensive Care Unit for their contribution to this study. Study was carried out in the Critical Care Unit, Logan Hospital, Queensland, Australia

\section{References}

1. Heyland DK, Dhaliwal R, Drover JW, Gramlich L, Dodek P: Canadian clinical practice guidelines for nutrition support in mechanically ventilated, critically ill adult patients. JPEN J Parenter Enteral Nutr 2003, 27:355-373.

2. Braunschweig CL, Levy P, Sheean PM, Wang X: Enteral compared with parenteral nutrition: a meta-analysis. $A m \mathrm{~J}$ Clin Nutr 2001, 74:534-542.

3. Kreymann KG, Berger MM, Deutz NE, Hiesmayr M, Jolliet $P$, Kazandjiev G, Nitenberg G, Berghe $G$ van den, Wernerman J, DGEM (German Society for Nutritional Medicine), Ebner C, Hartl W, Heymann C, Spies C, ESPEN (European Society for Parenteral and Enteral Nutrition): ESPEN Guidelines on Enteral Nutrition: Intensive care. Clin Nutr 2006, 25:210-223.

4. Moore FA, Moore EE, Jones TN, McCroskey BL, Peterson VM: TEN versus TPN following major abdominal trauma--reduced septic morbidity. J Trauma 1989, 29:916-922. discussion 922913.

5. Adams S, Dellinger EP, Wertz MJ, Oreskovich MR, Simonowitz D, Johansen K: Enteral versus parenteral nutritional support following laparotomy for trauma: a randomized prospective trial. J Trauma 1986, 26:882-891.

6. Moore FA, Feliciano DV, Andrassy RJ, McArdle AH, Booth FV, Morgenstein-Wagner TB, Kellum JM Jr, Welling RE, Moore EE: Early enteral feeding, compared with parenteral, reduces postoperative septic complications. The results of a meta-analysis. Ann Surg 1992, 216:172-183.

7. Zaloga GP: Parenteral nutrition in adult inpatients with functioning gastrointestinal tracts: assessment of outcomes. Lancet 2006, 367:1101-1111.

8. Marik PE, Zaloga GP: Early enteral nutrition in acutely ill patients: a systematic review. Crit Care Med 2001, 29:2264-2270.

9. Heyland DK, Tougas G, King D, Cook DJ: Impaired gastric emptying in mechanically ventilated, critically ill patients. Intensive Care Med 1996, 22:1339-1344.

10. Heyland DK, Drover JW, MacDonald S, Novak F, Lam M: Effect of postpyloric feeding on gastroesophageal regurgitation and pulmonary microaspiration: results of a randomized controlled trial. Crit Care Med 2001, 29:1495-1501.

11. Montejo JC, Grau T, Acosta J, Ruiz-Santana S, Planas M, GarciaDe-Lorenzo A, Mesejo A, Cervera M, Sanchez-Alvarez C, NunezRuiz R, Lopez-Martinez J: Multicenter, prospective, randomized, single-blind study comparing the efficacy and gastrointestinal complications of early jejunal feeding with early gastric feeding in critically ill patients. Crit Care Med 2002, 30:796-800.

12. Kaufman JP, Hughes WB, Kerstein MD: Pneumothorax after nasoenteral feeding tube placement. Am Surg 2001 67:772-773.

13. Kools AM, Snyder LS, Cass OW: Pneumothorax: complication of enteral feeding tube placement. Dig Dis Sci 1987, 32:1212-1213.

14. Wendell GD, Lenchner GS, Promisloff RA: Pneumothorax complicating small-bore feeding tube placement. Arch Intern Med 1991, 151:599-602.

15. Hernandez-Socorro CR, Marin J, Ruiz-Santana S, Santana L, Manzano JL: Bedside sonographic-guided versus blind nasoenteric feeding tube placement in critically ill patients. Crit Care Med 1996, 24:1690-1694

16. Hillard AE, Waddell JJ, Metzler MH, McAlpin D: Fluoroscopically guided nasoenteric feeding tube placement versus bedside placement. South Med J 1995, 88:425-428.

17. Rives DA, LeRoy JL, Hawkins ML, Bowden TA Jr: Endoscopically assisted nasojejunal feeding tube placement. Am Surg 1989, 55:88-91.

18. Shipps FC, Sayler CB, Egan JF, Green GS, Weinstein CJ, Jones $\mathrm{JM}$ : Fluoroscopic placement of intestinal tubes. Radiology 1979, 132:226-227. 
19. Thurlow PM: Bedside enteral feeding tube placement into duodenum and jejunum. JPEN J Parenter Enteral Nutr 1986, 10:104-105.

20. Heyland DK, Dhaliwal R, Day A, Jain M, Drover J: Validation of the Canadian clinical practice guidelines for nutrition support in mechanically ventilated, critically ill adult patients: results of a prospective observational study. Crit Care Med 2004, 32:2260-2266.

21. Gatt M, Macfie J: Bedside postpyloric feeding tube placement: A pilot study to validate this novel technique. Crit Care Med 2009, 37:523-527.

22. Salasidis R, Fleiszer T, Johnston R: Air insufflation technique of enteral tube insertion: a randomized, controlled trial. Crit Care Med 1998, 26:1036-1039.

23. Slagt $C$, Innes $R$, Bihari $D$, Lawrence J, Shehabi $Y$ : A novel method for insertion of post-pyloric feeding tubes at the bedside without endoscopic or fluoroscopic assistance: a prospective study. Intensive Care Med 2004, 30:103-107.

24. Lee AJ, Eve R, Bennett MJ: Evaluation of a technique for blind placement of post-pyloric feeding tubes in intensive care: application in patients with gastric ileus. Intensive Care Med 2006, 32:553-556

25. Villet S, Chiolero RL, Bollmann MD, Revelly JP, Cayeux RNM, Delarue J, Berger MM: Negative impact of hypocaloric feeding and energy balance on clinical outcome in ICU patients. Clin Nutr 2005, 24:502-509.

26. Fouque D, Guebre-Egziabher F: An update on nutrition in chronic kidney disease. Int Urol Nephrol 2007, 39:239-246.

27. Heyman JK, Whitfield CJ, Brock KE, McCaughan GW, Donaghy AJ: Dietary protein intakes in patients with hepatic encephalopathy and cirrhosis: current practice in NSW and ACT. Med J Aust 2006, 185:542-543.

28. Meduri GU: Diagnosis and differential diagnosis of ventilatorassociated pneumonia. Clin Chest Med 1995, 16:61-93.

29. Singh N, Rogers $P$, Atwood CW, Wagener MM, Yu VL: Shortcourse empiric antibiotic therapy for patients with pulmonary infiltrates in the intensive care unit. A proposed solution for indiscriminate antibiotic prescription. Am J Respir Crit Care Med 2000, 162:505-511.

30. Ho KM, Dobb GJ, Webb SA: A comparison of early gastric and post-pyloric feeding in critically ill patients: a meta-analysis. Intensive Care Med 2006, 32:639-649.

31. Marik PE, Zaloga GP: Gastric versus post-pyloric feeding: a systematic review. Crit Care 2003, 7:R46-51.

32. Kearns PJ, Chin D, Mueller L, Wallace K, Jensen WA, Kirsch CM: The incidence of ventilator-associated pneumonia and success in nutrient delivery with gastric versus small intestinal feeding: a randomized clinical trial. Crit Care Med 2000, 28:1742-1746.

33. Neumann DA, DeLegge MH: Gastric versus small-bowel tube feeding in the intensive care unit: a prospective comparison of efficacy. Crit Care Med 2002, 30:1436-1438.

34. Fruhwald S, Holzer P, Metzler H: Intestinal motility disturbances in intensive care patients pathogenesis and clinical impact. Intensive Care Med 2007, 33:36-44.

35. Tarling MM, Toner CC, Withington PS, Baxter MK, Whelpton R, Goldhill DR: A model of gastric emptying using paracetamol absorption in intensive care patients. Intensive Care Med 1997, 23:256-260.

36. Boivin MA, Levy $\mathrm{H}$ : Gastric feeding with erythromycin is equivalent to transpyloric feeding in the critically ill. Crit Care Med 2001, 29:1916-1919.

37. Kortbeek JB, Haigh PI, Doig C: Duodenal versus gastric feeding in ventilated blunt trauma patients: a randomized controlled trial. J Trauma 1999, 46:992-996. discussion 996-998.

38. Montecalvo MA, Steger KA, Farber HW, Smith BF, Dennis RC, Fitzpatrick GF, Pollack SD, Korsberg TZ, Birkett DH, Hirsch EF, et al.: Nutritional outcome and pneumonia in critical care patients randomized to gastric versus jejunal tube feedings. The Critical Care Research Team. Crit Care Med 1992, 20:1377-1387.

39. Nguyen NQ, Ng MP, Chapman M, Fraser RJ, Holloway RH: The impact of admission diagnosis on gastric emptying in critically ill patients. Crit Care 2007, 11:R16.

40. Kao CH, ChangLai SP, Chieng PU, Yen TC: Gastric emptying in head-injured patients. Am J Gastroenterol 1998, 93:1108-1112
41. Mentec H, Dupont H, Bocchetti M, Cani P, Ponche F, Bleichner G: Upper digestive intolerance during enteral nutrition in critically ill patients: frequency, risk factors, and complications. Crit Care Med 2001, 29:1955-1961.

42. Mutlu GM, Mutlu EA, Factor P: GI complications in patients receiving mechanical ventilation. Chest 2001, 119:1222-1241.

43. Ritz MA, Fraser R, Edwards N, Di Matteo AC, Chapman M, Butle R, Cmielewski P, Tournadre JP, Davidson G, Dent J: Delayed gastric emptying in ventilated critically ill patients: measurement by 13 C-octanoic acid breath test. Crit Care Med 2001, 29:1744-1749.

44. Zaloga GP: The myth of the gastric residual volume. Crit Care Med 2005, 33:449-450.

45. Deane A, Chapman MJ, Fraser RJ, Bryant LK, Burgstad C, Nguyen NQ: Mechanisms underlying feed intolerance in the critically ill: implications for treatment. World J Gastroenterol 2007, 13:3909-3917.

46. Esparza J, Boivin MA, Hartshorne MF, Levy $\mathrm{H}$ : Equal aspiration rates in gastrically and transpylorically fed critically ill patients. Intensive Care Med 2001, 27:660-664.

47. Davies AR, Froomes PR, French CJ, Bellomo R, Gutteridge GA Nyulasi I, Walker R, Sewell RB: Randomized comparison of nasojejunal and nasogastric feeding in critically ill patients. Crit Care Med 2002, 30:586-590.

48. Griffith DP, McNally AT, Battey CH, Forte SS, Cacciatore AM, Szeszycki EE, Bergman GF, Furr CE, Murphy FB, Galloway JR, Ziegler TR: Intravenous erythromycin facilitates bedside placement of postpyloric feeding tubes in critically ill adults: a double-blind, randomized, placebo-controlled study. Crit Care Med 2003, 31:39-44.

49. Ugo PJ, Mohler PA, Wilson GL: Bedside postpyloric placement of weighted feeding tubes. Nutr Clin Pract 1992, 7:284-287.

50. Gabriel SA, Ackermann RJ: Placement of nasoenteral feeding tubes using external magnetic guidance. JPEN J Parenter Enteral Nutr 2004, 28:119-122.

51. Gray R, Tynan C, Reed L, Hasse J, Kramlich M, Roberts S, Suneson J, Thompson J, Neylon J: Bedside electromagnetic-guided feeding tube placement: an improvement over traditional placement technique? Nutr Clin Pract 2007, 22:436-444.

52. Levy $\mathrm{H}$, Hayes J, Boivin M, Tomba T: Transpyloric feeding tube placement in critically ill patients using electromyogram and erythromycin infusion. Chest 2004, 125:587-591.

53. Young RJ, Chapman MJ, Fraser R, Vozzo R, Chorley DP, Creed S: A novel technique for post-pyloric feeding tube placement in critically ill patients: a pilot study. Anaesth Intensive Care 2005 33:229-234. 